\title{
AGENESIS OF THE ISTHMUS OF THE THYROID GLAND WITH RIGHT LATERAL THYREO GLANDULARIS
}

Sreekanth Tallapaneni, Simmi Soni, Syed Shakir Noman, Mohammad Irfan Ali, Faraz Adil

Hashmi

1. Associate Professor. Department of Anatomy, Shadan Institute of Medical Sciences teaching Hospital \& Research Centre.

2. Associate Professor. Department of Anatomy, Dr. V.R. K. Women's Medical College teaching Hospital \& Research Centre.

3. Associate Professor. Department of Pathology, Shadan Institute of Medical Sciences teaching Hospital \& Research Centre.

4. II Year MBBS Student. Shadan Institute of Medical Sciences teaching Hospital \& Research Centre.

5. II Year MBBS Student. Shadan Institute of Medical Sciences teaching Hospital \& Research Centre.

\section{CORRESPONDING AUTHOR:}

Sreekanth. Talla Paneni,

237/2RT (10-3-799),

Vijayanagar Colony,

Hyderabad- 500057.

E-mail: anatomysreekanth18@yahoo.com

Ph: 00919848826008.

ABSTRACT: Among the human endocrine glands the H Shaped Brownish Red thyroid gland is well known for its disturbed organogenesis leading to a wide variety of morphological variations ranging from commonly occurring thyroglossal duct cyst and persistence of pyramidal lobe and rarely seen hypoplasia, ectopy, hemiagenesis \& agenesis of isthmus. During the Routine Prosection hours an Elderly male cadaver showed agenesis of isthmus of thyroid gland exposing the Arch-anterior part of cricoid cartilage \& the upper four tracheal rings the two lateral lobes of the gland were seen as two separate lobes without any nexus between them. The LGT was seen arising from the upper part of anterior border of the thyroid cartilage and got inserted into the substance of the right lobe along the lower $2 / 3^{\text {rd }}$ of its anterior border. Hence the LGT is aptly termed as Thyreoglandularis type. There was no supra isthmic arterial arcade formed by the anterior branches of the right and left superior thyroid arteries. There was no ectopic thyroid tissue present in the neck along the course of thyroglossal duct from the root of the tongue to the glands position The agenesis of the isthmus with right lateral LGT are very rare morphological variations and only scanty cases have been documented in the literature. In the present era of machine vision, various non-invasive radiological investigations such as USG, CT, MRI can bring into light, these otherwise clinically silent variations. Once suspected the subject can be directed for a thorough screening of differential diagnosis such as autonomous thyroid nodule, thyroiditis, neoplastic masses and infiltrative diseases like amyloidosis.

KEYWORDS: Isthmus, Agenesis, Ectopia, Thyreoglandularis, Hemiagenesis, thyroglossal duct

INTRODUCTION: A H-shaped, brownish red, highly vascular thyroid gland is located anterior to trachea and midway between the apex of thyroid cartilage and suprasternal notch. Important neighboring posterior structure include four para thyroid glands situated behind the pear shaped lobes and recurrent laryngeal nerves coursing along trachea. The isthmus connects the lower parts of the lobes, measuring $1.2 \mathrm{~cm}$ transversely and vertically. It extends from second 
and third tracheal rings often higher or at times lower. (1) The superior thyroid arteries anastomose along its upper border A conical pyramidal lobe often ascends towards the hyoid bone from isthmus or the adjacent part of either lobe (more often left). A glandular or fibrous or fibro muscular band, the levator of the thyroid gland (musculus levator glandulae thyroidea) usually originates from the hyoid bone and rarely from the thyroid cartilage and gets inserted into the apex of the pyramidal lobe or upper border of isthmus or directly into the substance of the gland which is very rare. It can be unilateral or bilateral more frequently arising from the left lobe it can be Glandular, Fibrous, Fibro-muscular with one or two or three slips, it is thought to represent the detached part of infrahyoid muscles, may be innervated by a twig from ansa cervicalis.

EMBRYOLOGICAL BASIS: It is the first endocrine gland which appears and begins to function at approximately by the end of $3^{\text {rd }}$ month, at which time the first follicles containing colloid become visible. (2) the appearance in the fourth week of embryonic life is a endodermal nodule at the apex of foramen caecum on developing tongue the nodule descends through the neck at the end of a slender thyroglossal duct which breaks down by the end of $5^{\text {th }}$ week and continues its descent to reach its definitive position by $7^{\text {th }}$ week. The commonest evidence of embryologic thyroid descent is the small pyramidal lobe projecting upwards from the isthmus more commonly on left than on right side. Agenesis of the isthmus can be explained with embryological background. Phylogenetically the thyroid follicles are structured to acquire by lobe shaped with an isthmus in between them. (3) In the lower animals like amphibians, birds and among mammals - monotremes, certain Marsupials, Cetaceans, Carnivores and Rodents the absence of isthmus is consider to be normal. (4) Mori (1964) after ob serving 210 Neck dissections classified the LGT's into five types starting from the origin to the insertion. They are a) Hyopyramidalis, b) Thyreopyramidalis, c) Thyreoglandularis, d) Hyoglandularis, and e) Tracheoglandularis. (5)

MATERIALS AND METHODS: The present variation was observed in the Department of Anatomy at Shadan Institute of Medical Sciences Teaching Hospital and Research Centre, Peerancheru, Hyderabad, Andhra Pradesh. during the routine Dissection hours for the first year M.B.B.S students. An embalmed elderly male cadaver most probably in the sixth decade with no scars in the anterior cervical region suggesting that the subject when alive had not undergone any neck surgery served the purpose of being the material used. The routine dissection instruments such as scalpel, blade, surgical and Anatomical forceps were used. The method of Dissection began with a median incision made from the chin downwards to the supra sternal notch with a scalpel. A horizontal incision is made along the posterior border of the base of the mandible till the mastoid process and the skin flaps were raised and reflected laterally. Another horizontal incision is given along the upper border of the clavicle. Platysma a subcutaneous muscle which is also reflected along with the cutaneous nerves lying in the superficial fascia of the neck. The supra hyoid and the infra hyoid group of muscles on each side of the median plane are identified. The sternocleidomastoid muscles of both the sides are cut through their origin and reflected upwards; the deeper structures including thyroid gland and trachea are seen. The carotid triangle formed between posterior belly of the digastrics muscle and the stylohyoid (Anterosuperiorly) Superior belly of omohyoid (Anteroinferiorly) and Anterior border of the sternocleidomastoid muscle (Posteriorly) is defined and the contents (The common carotid artery, the internal carotid artery, the external carotid artery, internal jugular vein, vagus nerve, superior laryngeal branch, spinal accessory nerve) are all being 
identified. From the surface of trachea, fibrous remains of the thymus gland were removed. Surprisingly the arch i.e., the anterior part of the cricoid cartilage and tracheal rings (upper four) were seen and the two lateral lobes of thyroid were discovered on either side of the trachea

OBSERVATION: During the routine prosection hours of the $1^{\text {st }}$ Year M.B.B.S Students in the department of the anatomy and an elderly male cadaver reveled buried deep to the infra hyoid muscles the thyroid gland as separate right lateral and left lateral lobes without any type of nexus between the two lateral lobes. There was complete absence of isthmus exposing the median structures namely the arch formed by the anterior part of the cricoid cartilage with it convexity projecting forwards along with upper four tracheal rings. Fig (1). Both the lobes were brownish red in color the right lateral lobe was conical in shape in apex directed laterally. The right superior thyroid artery (STA) arising from right external carotid artery (ECA) was seen close to the apex fig (2) The LGT which represents the persisting and of the thyroglossal duct instead of arising from hyoid gland was originating from the upper part of anterior border of the thyroid cartilage a little distance towards the right from the thyroid notch. The LGT got inserted into the substance of right lateral lobe of the thyroid gland directly along the lower $2 / 3^{\text {rd }}$ of its anterior border hence the LGT is aptly termed as thyreoglandularis fig(3) at the site of insertion a small part of LGT was seen merging with lower $1 / 3^{\text {rd }}$ the anterior border was glandular the remaining part of the LGT was entirely fibrous. Fig (4) the LGT neither had any innervation nor any blood supply each lateral lobe was supplied by the branches of superior thyroid artery and inferior thyroid artery of the same side. The left lateral lobe of the thyroid gland was triangular rather than being conical. Fig (5) There was no supra isthmic arterial anastomoses between the anterior branches of the right and left superior thyroid arteries. there was no pyramidal lobe seen. No ectopic thyroid tissue was seen in the cervical region along the course of thyroglossal duct from the root of tongue to the glands position and in the neighbouring vicinity

DISCUSSION: According to GRUBER (quoted by Testut et.al., 1978) the incidence of agenesis is about 5\%, (6) and Allan stated it to be ranging from 2.0-4.0\% (7) but according to Marshall (1895) it is about $15 \%$. (8) JOSHI SD, reported the incidence to be little higher i.e., $16.66 \%$. (9) After studying 105 human thyroid glands (88 male \& 17 female) RANADE A.V opined the incidence of ageneses to be about 33\% ageneses of thyroid gland was seen in 27 male cadavers and 8 female cadavers. ( 10 ) In the present case the ageneses was seen in a male cadaver. It is an uphill task to determine the incidence of agenesis of thyroid isthmus because it is usually diagnosed in cohort of individual presenting with other thyroid pathologies. After reviewing world literature, of thyroid hemiagenesis) MELNICK reported It to be 50\%. (11) Also, according to MIKOSCH(after reviewing 256 cases of thyroid hemiagenesis ) reported absence of isthmus to be $50 \%$. ( 12 ) reports in the wide literature suggest that chromosome 22 play a important role in the thyroid development was suggested by Gangbo E, (13) .

JOSHI SD, reported the incidence of LGT to be 30\% ( 9 ). According to SULTANA SZ, the incidence of LGT in Bangladeshi cadavers is 43.33\% (14) and according to RANADE A V, the incidence is $49.5 \%$ In Indian cadavers. (10) According to STANDRING, (2006)the LGT extends from the pyramidal lobe or the upper border of the isthmus usually on the left side, to the body of hyoid bone above. (15) In the present case the LGT was present on the right side and originated from the upper border of the thyroid cartilage. According to GREGORY and 
GUSE, SOMMERINGS the LGT is an accessory muscle which runs from the hyoid bone to insert partly on to the thyroid cartilage and partly on the isthmus of the thyroid gland (16). In the present case the insertion was directly into the substance of the gland along the anterior border MERKEL suggested that the LGT was glandular and usually surrounded by muscle fibres. (17) But HUSCHKE thought it was wholly a glandular structure, no mention about the muscle component was made. (18) BOURGERY ---- described and illustrated a muscle, which he called as HYO-THYROIDIEN, occupying the place of pyramidal lobe. (19) GODART reported and also proved the LGT in a case to be muscular by conducting a NITRIC ACID TEST (20). LOUKAS M, reported, -- a unilateral LGT in a 83 year old Caucasian female cadaver with three muscular strips. Also the LGT had a TWIG from the ansa cervicalis supplying it. Also the LGT was supplied by a branch from the Superior thyroid artery (STA)\& a large tributary of the inferior thyroid vein (ITV) was seen posterior to it ( 21 ). In the present case the LGT did not have any nerve supply or blood supply. SAADEH et al reported an unusual case of LGT in a female cadaver which extended from the mastoid process (origin) extended superficially to the superior belly of the omohyoid muscle to the connective tissue of left lobe of the thyroid gland (Insertion). In the present case the LGT was mostly fibrous with very small glandular component. Absolutely there was no muscle tissue. (22) Devi Shankar reported the Agenesis of isthmus of thyroid gland with two pyramidal lobes; each one of them had levator glandulae thyroidae. (23). In the present case there was total agenesis of isthmus with no pyramidal lobes at all and the LGT was unilateral. Gunapriya R, documented a case report of thyreoglandularis arising on the right side. With absence of pyramidal lobe (24) the present case report is in accordance with her case report.

CONCLUSION: In the era of machine vision the horizon for the identification of the agenesis of isthmus is opening up as the reporting is possible by simple non-invasive techniques like Scintigraphy, Ultrasonography, C.T. Scan, M.R.I. Scan and not just at Time of Surgery on the Operating Table. When it is suspected the subject should be motivated for the compulsory screening of the differential diagnosis ranging from the simple to complicated pathologies like Thyroiditis Autonomous Thyroid Nodule Primary Carcinoma Neoplastic Metastasis Infiltrative Disease - Amyloidosis. The study of thyroid anatomy along its associated frequently to rarely occurring anatomical variations form a corner stone for safe and effective thyroid surgery

\section{ACKNOWLEDGEMENTS:}

1. Thanks to Dr. Sarib Rasool Khan SAB, Our Managing Director, a towering personality for all his encouragements \& inspiration towards Research Work.

2. Thanks to J. George Williams \& his family for typing the manuscript.

3. Thanks to Srinivas Pratipati, I MBBS Student for technical support.

\section{REFERENCES:}

1. Williams PL, Bannister LK<, Berry MM, Collins P, Dison M, Dussek JE, Ferguson MWJ. Grace Anatomy, 38 th Ed, Edingubh, Churchill living stone 2000, 1891- 1897.

2. Mario De Felice and Roberto Di Lauro. Anatomy and development of Thyroid gland, Leslie. J Degroot. J. Larry - jameson. Endorinology 5th Edn Vol - 2 91 Pg; 1785 - 1787.

3. T.W Saddler. Langmans Medical Embryology 11 th Edn pg; 278 - 279

4. Pastor Vazquez JF, Gil Verona JA, De Paz Fernandez FJ, Barbosa Cachorro M. Agenesis of the thyroid isthmus. Eur J Anatomy, 2006; 10: 83-84. 
5. Mori M (1964) Statistics on the musculature of the Japanese. Okajimas Folia Japan, 40: 195-300.

6. Testut L, Latarjet A. Anatomia Humana. Tomo IV. Ed. Barcelona, Salvat. 1978: 402-404. Spanish.

7. Allan FD. An accessory or superficial inferior thyroid artery in a full term infant Anatomy Rec 1952; 112-53

8. Marshall CF. Variation in the form of the thyroid in man. J Anat Physiol. 1895; 29: 234239.

9. Joshi SD, Joshi SS, Daimi SR, Athavale SA J2010) The thyroid gland and its variations: a cadaveric study. Folia Morpologica 69:47-50

10. Ranade AV, Rai R, Pai MM, Nayak SR, Prakash, Krishnamurthy A, Narayana S (2008) Anatomical variations of the thyroid gland: possible surgical implications. Singapore Med J 49:831-834.

11. Melnick JC, Stemkowski PE: Thyroid hemiagenesis (hockey sticsign): A review of the world literature and report of four cases. J Clin Endocrinol Metab 1981, 52: 247-251.

12. Mikosch P, Gallowitsch HJ, Kresnik E, Molnar M, Gomez I, Lind P: Thyroid hemiagenesis in an endemic goiter area diagnosed by ultrasonography: Report of sixteen patients. Thyroid 1999, 9(11): 1075-84.

13. Gangbo E, Lacombe D. alberti EM et al. Trisomy 22 with thyroid isthmus agenesis and absent gall bladder. Genet couns 2004; 15: 311-5.

14. Morphological study of levator glandulae thyroidea in Bangladeshi cadaver.Sultana SZ, Khalil M, Khan MK, Shamim R, Parveen S, Ara ZG. Department of Anatomy, Mymensingh Medical College, Mymensingh, Bangladesh.

15. Standring S (2006) In: Gray's Anatomy, 39th Edition, London: Elsevier Chruchill Livingstone. 561.

16. Gregory JK Guse DM. Unique variant of levator glandulae thyroideae muscle. Clin. Anat 2007; 20-966-7.

17. Merkel FS. Die Anatomie des Menschem mit Hinweisen aufdie arztliche Praxis, Abt. 3. Wiesbaden: JF Bergman, 1913: 50 German.

18. Huschke E. Traite de splanchnologic et des organs des sens. In: Encyclopedie anatomique. Vol V. Paris JB Bailliere. 1845: 274.

19. Bourgery JM Traite complet d' anatomic de I'homme, comprenant la medicine operatoire, avec planches lithographiees d' après nature par NH Jacob. Atlas Paris C. [-A] Delaunay 1831; Tome II: 90, 1836; Tome IV; 91. French.

20. Godart J. Muscle de la glande thyroide, muscle de Duvernoi, musculus levator glandulae thyreoideae. (Exemple du Soemmerring.) [Abstr.] Bull Soc anat Paris 1847:22:202-5 French.

21. Loukas M. Merbs W, Tubbs RS, Curry B, Jordan R. Levator glandulae thyroideae muscle with three slips. Anat Sci Int. 2008 Dec; 83 I4) 273-276.

22. Saadeh FA, Kawas SH, Haikal FA, Hawi JS. An unusual levator glandulae thyroideae: a case report and literature review. J Anat Soc Ind 1996; 45:125-8.

23. Devi sankar K, Sharmila Bhanu P, Susan PJ, Gajendra K. Agenesis of isthmus of thyroid gland with bilateral levator glandulae throideae : International Journal of Anatomical Variations (2009) 2;29-30 
24. Gunapriya R, Varsha S, Senthilk Kumar B. Levator Glandulae Thyroideae with the absence of Pyramidal Lobe -A case report.; Internation Journal of Anatomical Sciences 2010, 1: 45-47

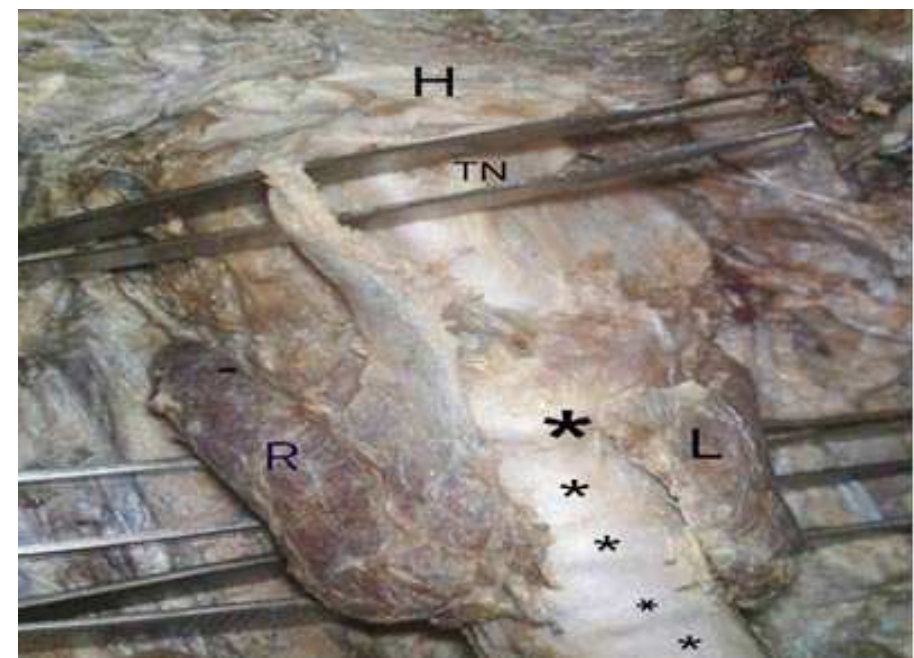

Fig (1) ANTERIOR VIEW OF THE NECK DISSECTION R-RIGHT LOBE, L-LEFT LOBE, H-HYOID TN THYROID NOTCH

The right and left lobes are seen as separate lobes with no nexus between them. Thus exposing the median structures i.e. bigger star representing the arch of cricoids cartilage and many smaller stars representing the tracheal rings.

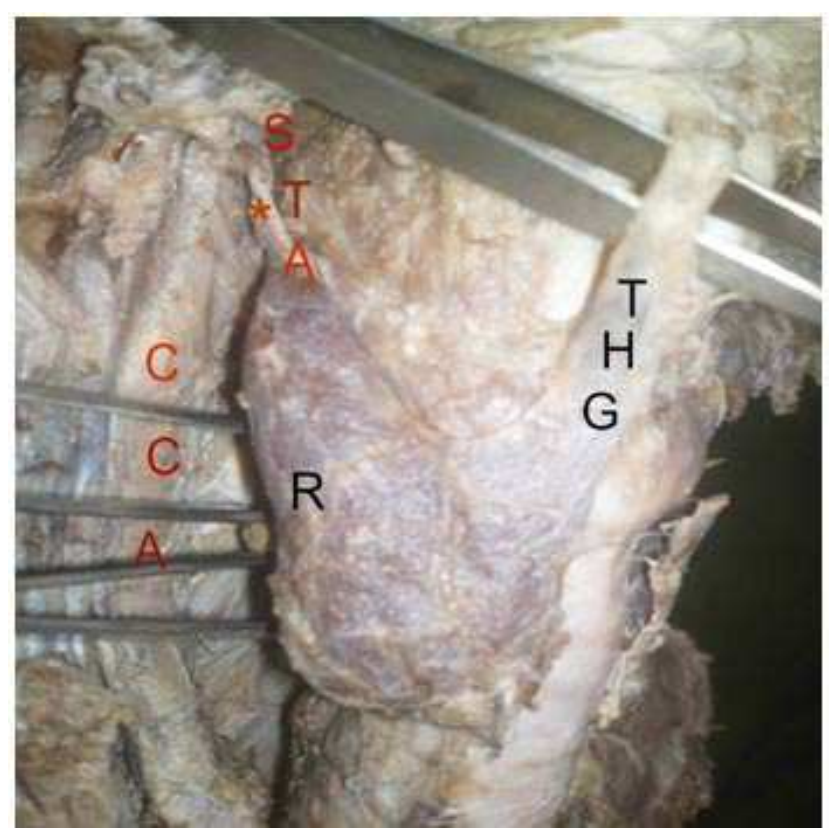

Fig (2)THE RIGHT LATERAL VIEW NECK DISSECTION. R- RIGHT LOBE, THG THYREOGLANDULARIS, CCA COMMON CAROTID ARTERY, STA SUPERIOR THYROID ARTERY

The right lateral lobe appearing conical in shape. The right STA arising from right ECA is seen closed to the apex of the right lobe. The right CCA (common carotid artery is seen behind the prongs of the pair of forceps 


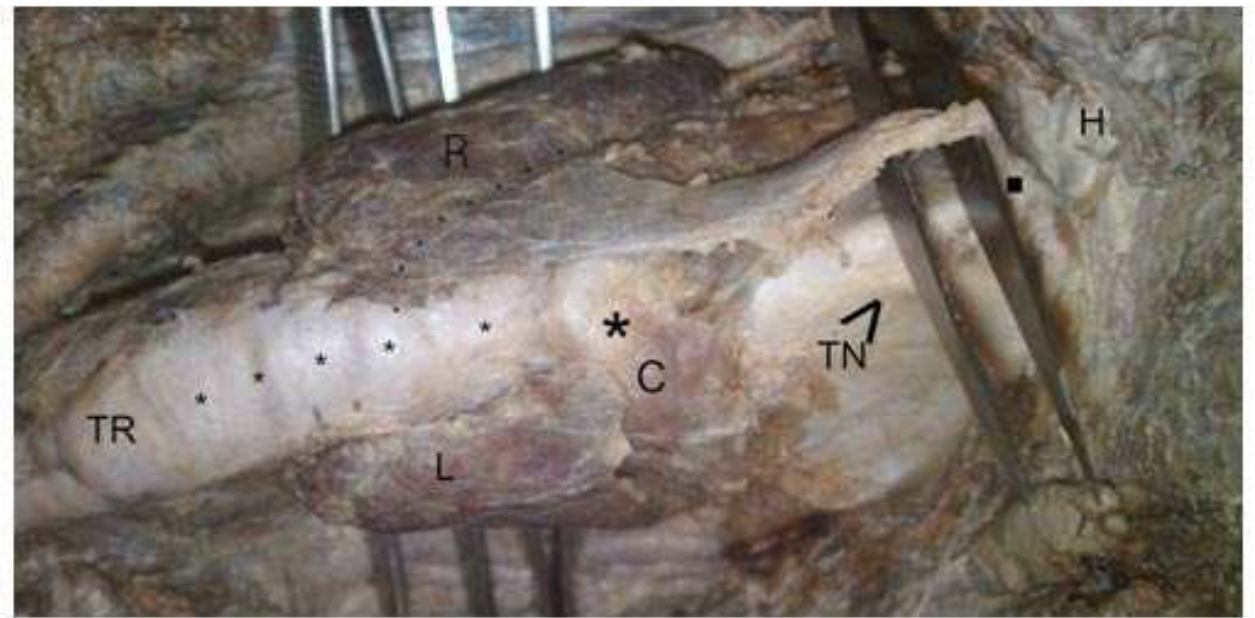

Fig (3) SUPERIOR VIEW OF NECK DISSECTION TN- THYROID NOTCH, C-ARCH OF CRICOID CARTILAGE. TR- TRACHEAL RINGS, H-HYOID BONE

The origin of thyreoglandularis from the upper border of thyroid cartilage, little towards the right from the thyroid notch. The hyoid bone $(\mathrm{H})$ is seen with no attachment of LGT. Large dot represent the origin. The dots represent the Median structures i.e., the arch of cricoids cartilage and tracheal rings are exposed due to agenesis of isthmus.

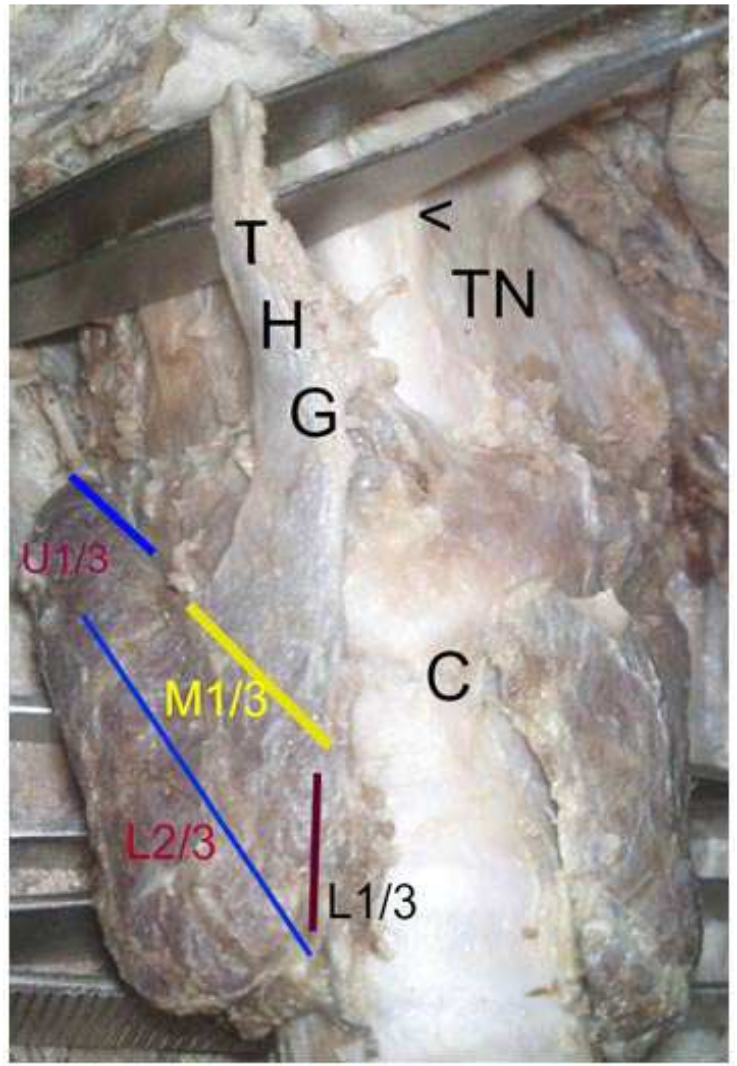

Fig (4) RIGHT ANTERIOR VIEW OF NECK DISSECTION - ZOOM IN 


\section{C-ARCH OF CRICOID CARTILAGE.}

The thick short blue line represents upper $1 / 3^{\text {rd }}$ of anterior border.

The thinner and longer blue line represent the lower $2 / 3^{\text {rd }}$ of the anterior border of right lobe. The yellow line represents the middle $1 / 3^{\text {rd }}$ of the anterior border which received the insertion of the fibrous component of THG.

The brown line represents the lower $1 / 3^{\text {rd }}$ of the anterior border which received the insertion of the glandular component of THG

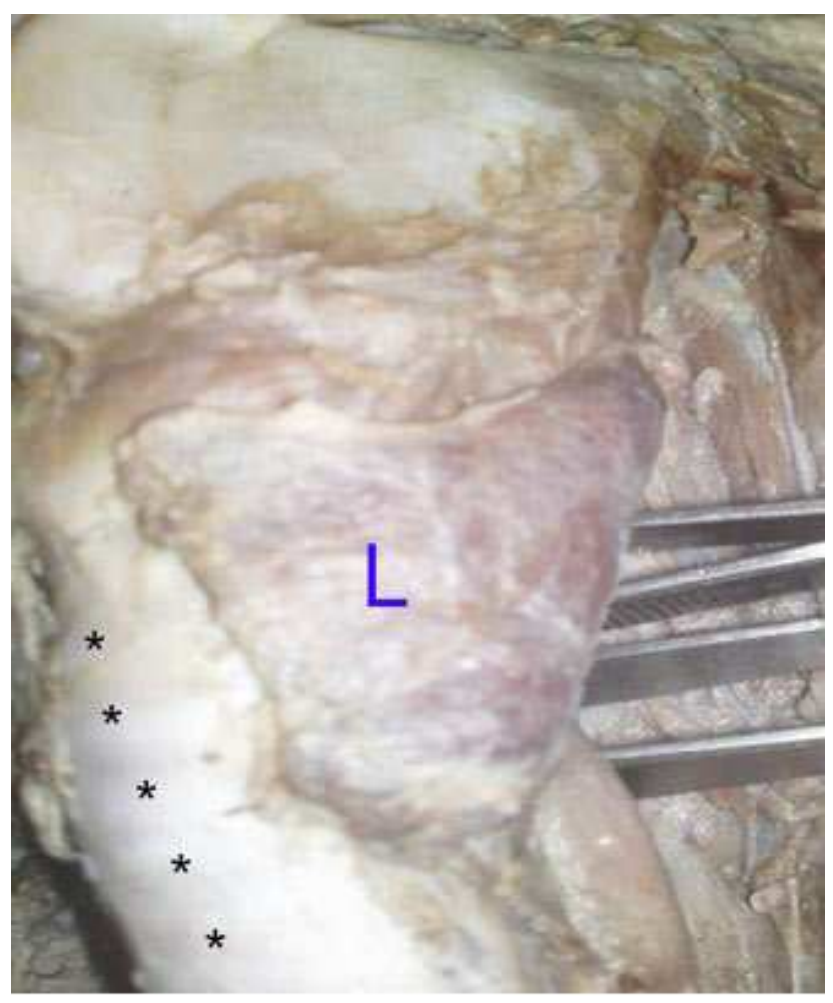

Fig (5) LEFT LATERAL VIEW OF THE NECK DISSECTION

Left lateral lobe of thyroid gland - triangular in shape. The astericks indicates the tracheal rings. 